\title{
Surface hardening of titanium alloy by minerals
}

\author{
A. V. Skazochkin ${ }^{1, \dagger}$, A.S. Useinov ${ }^{2}$, S. V. Kislov ${ }^{3}$ \\ †avskaz@rambler.ru
}

${ }^{1}$ Kaluga Branch of the Russian Presidential Academy of National Economy and Public Administration, 4 Okruzhnaya st. (building 3), Kaluga, 248021, Russia

${ }^{2}$ Technological Institute for Superhard and Novel Carbon Materials, 7a Centralnaya st., Troitsk, 142190, Russia

${ }^{3}$ Scientific and Production Center “Mico-Tech" Limited Liability Company, 95 Leninsky ave., Moscow, 119313, Russia

A comparative study of wear resistance, hardness and elastic modulus in samples of VT6 titanium alloy with a mineral coating created using low-temperature technological operations (local heating up to $80^{\circ} \mathrm{C}$ ) and without coating was performed. The hardness and elastic modulus in nanoindentation mode were measured by applying a series of indentations with various maximum loads. The load was selected in a way that penetration depth of the tip into the material ranged from $500 \mathrm{~nm}$ to $4 \mu \mathrm{m}$ with an estimated thickness of the modified layer of about $10 \mu \mathrm{m}$. The creation of a mineral layer increased the hardness of the surface of the titanium alloy sample by $45-70 \%$ and also caused a $2-3$ times increase of the roughness parameters of samples. Taking into account the specific features of measuring physical and mechanical properties of thin modified layers, wear resistance was measured using the method of multi-cycle friction with a sapphire sphere, while controlling the clamping force and deepness of the tip penetration into the sample. Wear resistance of the surface of the sample modified by minerals increased by $4-5$ times as compared to the wear resistance of the surface of the VT6 titanium alloy without a modification. By authors' opinion, the results of the studies reveal big potentials of using metal parts from titanium and titanium alloys with mineral coatings in various devices and mechanical assemblies.

Keywords: surface modification, wear resistance, hardness.

УДК 621.793 .74

\section{Поверхностное упрочнение титанового сплава минералами}

\author{
Сказочкин А. В. ${ }^{1, \dagger}$, Усеинов А.С. ${ }^{2}$, Кислов С. В. ${ }^{3}$
}

${ }^{1}$ Калужский филиал Российской академии народного хозяйства и государственной службы при Президенте Российской Федерации, ул. Окружная 4, корп.3, Калуга, 248021, Россия

${ }^{2}$ Технологический институт сверхтвердых и новых углеродных материалов, ул. Центральная 7а, Троицк, 142190, Россия ${ }^{3}$ Научно-производственный центр «Технологии минеральных покрытий», Ленинский пр-т 95, Москва, 119313, Россия

Проведено сравнительное исследование износостойкости, твердости и модуля упругости образцов из титанового сплава ВТ6 с минеральным покрытием, созданным при использовании низкотемпературных технологических операций (с локальным нагревом до $80^{\circ} \mathrm{C}$ ), и без покрытия. Измерения твердости и модуля упругости в режиме наноиндентирования были проведены путем нанесения серии уколов с различной максимальной нагрузкой. Нагрузка подбиралась таким образом, чтобы глубина внедрения наконечника в материал составляла от 500 нм до 4 мкм при оценочной толщине модифицированного слоя около 10 мкм. Создание минерального слоя увеличило твердость поверхности образца из титанового сплава на 45-70\%, а также увеличило параметры шероховатости образцов в 2-3 раза. Корректность измерения определяется тем, что на малых глубинах влияние подложки на измеряемые величины мала, и поэтому ею можно было пренебречь. Разброс данных сопоставим с измеряемыми величинами, что, возможно, связано с относительно большой шероховатостью образцов. Учитывая особенности измерения физико-механических свойств тонких модифицированных слоев, измерение износостойкости было выполнено методом многоциклового трения сапфировой сферой с контролем силы прижима и углубления наконечника в образец. Использование такой системы измерения особенно важно при испытании тонких слоев, когда толщина слоя сопоставима с параметрами шероховатости поверхности. Износостойкость поверхности образца, модифицированной минералами, увеличилась в 4-5 раз по сравнению с износостойкостью поверхности титанового сплава ВТ6 без модификации. По мнению авторов, результаты исследования открывают большие потенциальные возможности использования металлических деталей из титана и титановых сплавов с минеральными покрытиями в различных устройствах и механизмах.

Ключевые слова: модификация поверхности, износостойкость, твердость. 


\section{1. Введение}

Коррозионная стойкость, высокая удельная прочность и жаропрочность обусловили широкое распространение титана и его сплавов во многих отраслях промышленности. Использование титана и его сплавов ограничивает низкое сопротивление изнашиванию [1]. Основная причина склонности к налипанию и задиранию титановых сплавов состоит в том, что при достаточно интенсивном трении тонкая оксидная пленка на поверхности титана быстро разрушается, возникает задирообразование - титан налипает на поверхность ответной детали, и деталь вязнет [1-2]. Существование на поверхности титана и сплавов пленки окислов, являющейся причиной коррозионной стойкости, создает проблемы при создании надежных износостойких покрытий некоторыми традиционными способами из-за низкой адгезии и появления дефектов. Тем не менее, существуют способы упрочнения поверхности титана и его сплавов, минимизирующие склонность к налипанию. Повышение износостойкости титана традиционно осуществляют такими методами модификации поверхности, как азотирование, цементация, термическое оксидирование, для которых наличие поверхностной пленки из окислов не является препятствием. Однако эти методы малоэффективны как с точки зрения технических параметров, так и экономически, потому что сопровождаются длительным высокотемпературным нагревом, ограничением массогабаритных размеров, хрупкостью получаемых слоев. Высокие температуры могут приводить к изменению структуры металла, снижению прочностных свойств, поводкам и низкому выходу годного [1]. Поэтому актуальным является развитие других методов модификации поверхности титана и сплавов с минимальным или низким термическим воздействием, в частности, методов ионной имплантации, электроискрового легирования, микродугового оксидирования, технологии минеральных покрытий.

К методам, использующим низкотемпературные операции при создании модифицированного слоя, относится так называемая технология минеральных покрытий [3]. Суть технологии заключается в создании модифицированного поверхностного слоя толщиной 5-30 мкм путем его пластического деформирования с помощью ультразвукового и механического воздействий, активирующих вхождение ультрадисперсных частиц минералов в объем металла [4-5].

Базовая процедура модификации поверхности металла по технологии минеральных покрытий состоит из четырех этапов [4]: электроискровая обработка поверхности; текстурирование поверхности; внедрение ультрадисперсных частиц в поверхностный слой при помощи ультразвуковой установки; использование шариковых и роликовых накаток при обработке поверхности. В результате формируется поверхностный слой, имеющий высокие антифрикционные, износостойкие, противозадирные свойства $[4,7]$. Базовая технология служит основой для дальнейшей разработки маршрутных и рабочих технологий, в том числе являющихся ноу-хау, для получения необходимых характеристик поверхностных слоев.
Технология не изменяет геометрические размеры деталей, минеральные слои могут быть созданы локально, все технологические операции проводятся на воздухе при комнатной температуре, локальный нагрев не превышает $80^{\circ} \mathrm{C}[4,6]$. Микроструктурные исследования показали, что в результате модификации поверхности по технологии минеральных покрытий наблюдается поверхностный слой с четко отличной от объемной зернистой структурой [4]. Трибологические испытания показали, что модифицированная поверхность образцов из стали и титана приобретает высокую твердость [4], износостойкость пар трения из стали увеличивается от 3 до 10 раз [7], стабилизируется коэффициент трения образцов из стали в диапазоне $30-140^{\circ} \mathrm{C}$ [8], образцы выдерживают испытание на пластичность (2-х угловой изгиб с прогибом 0,5 мм, соответствует ГОСТ Р 9.317-2010, п. 5.2). Стендовые и эксплуатационные испытания деталей из стали с минеральными покрытиями продемонстрировали отсутствие признаков схватывания и минимизацию налипания [9]. При этом наличие окисной пленки или наплавок, например, на поверхности деталей из хромсодержащих коррозионно-стойких сталей, не является препятствием для создания износостойких минеральных покрытий [10]. Все это указывает на то, что технология минеральных покрытий может быть эффективным инструментом создания слоев на образцах из титана и титановых сплавов для повышения их износостойкости.

Цель настоящей работы - сравнительное исследование некоторых трибологических параметров образца из титанового сплава ВТ6 с минеральным покрытием, созданным при использовании низкотемпературных технологических операций, и образца без покрытия: износостойкости, твердости и модуля упругости.

\section{2. Материалы и методики}

Два образца из прутков титанового сплава ВТ6 (ГОСТ 19807-91) были изготовлены токарной обработкой без шлифовки в виде дисков толщиной 10 мм, диаметром 33 мм с отверстием в середине диаметром 11 мм. На поверхности одного из образцов был создан модифицированный минеральный слой по базовой технологии НПО «Геоэнергетика». Толщина модифицированного слоя, исходя из технологических параметров при его создании и ранее проведенных экспериментов, была около 10 мкм [4]. На образцах были выполнены сравнительные измерения рельефа и шероховатости поверхности, твердости и модуля упругости (Юнга), износостойкости.

Измерение шероховатости поверхности проводилось на профилометре (модель 130, предприятие-изготовитель «ПРОТОН МИЭТ»). Использовались следующие параметры процедуры измерения: длина профиля 12,5 мм, скорость измерения профиля $-0,5 \mathrm{mм} / \mathrm{c}$.

Измерение твердости и модуля упругости проводилось с помощью нанотвердомера «НаноСкан-4D» [11 - 12]. Метод измерения - вдавливание алмазной пирамиды с регистрацией диаграммы вдавливания и последующим расчетом твердости и модуля упругости 
в соответствии с ГОСТ 8.748-2011 (ISO 14577), который часто называют методом инструментального индентирования.

Измерения проводились индентором в виде трехгранной пирамиды типа Беркович, время нагружения 10 c, время разгружения - 10 с, время поддержания максимальной нагрузки -2 с, максимальная нагрузка $20-1500 \mathrm{мH}$.

Существует проблема корректности измерения физико-механических свойств тонких покрытий и тонких модифицированных слоев [13], возникающая из-за наличия факторов, приводящих к методическим ошибкам для некоторых методов измерения износостойкости, твердости, модуля упругости. Наиболее значительными факторами являются шероховатость поверхности, остаточные напряжения и влияние подложки. Влияние подложки или объема основного металла состоит в том, что для системы модифицированный слой - основной металл регистрируемый отклик материала при измерении зависит от свойств и слоя, и объема металла.

В типичных методах трибологических испытаний нормальная нагрузка прикладывается пассивным образом путем установки груза соответствующей массы. Недостатком такого способа является проявление эффектов прерывистого контакта наконечника с поверхностью вследствие инерционности системы нагрузки. Особенно остро это проявляется на шероховатых поверхностях, для которых наконечник «перескакивает» с одного выступа неровности поверхности на другой в процессе движения образца или измерительной глтовки прибора при истирании. Таким образом, по мере истирания материала меняются условия контакта, что приводит как к возможным некорректным результатам, так и большому разбросу значений.

Измерение износостойкости было выполнено с помощью сканирующего твердомера «НаноСкан-4D» методом многоциклового трения сапфировой сферой с контролем силы прижима и углубления наконечника в образец [13-14]. Применение метода склерометрии при истирании в приборе НаноСкан позволяет с помощью высокоскоростной системы обратной связи обеспечить активное поддержание заданной нагрузки в каждой точке траектории при истирании. Если наконечник пе- реходит с локального пика на впадину, система нагрузки прижимает или оттягивает измерительную головку, чтобы условия контакта выдерживались постоянными. Кроме того, исключается возможность локальных ударных нагрузок, характерных для пассивного задания нормальной нагрузки. Использование такой системы измерения особенно важно при испытании тонких слоев, когда толщина слоя сопоставима с параметрами шероховатости поверхности.

Были использованы следующие параметры процедуры измерения: радиус закругления острия сапфирового наконечника - 42 мкм, длина трека износа 1 мм, количество циклов возвратно-поступательного движения -100 , сила нагружения при испытании $-100 \mathrm{мH}$ и $500 \mathrm{mH}$, скорость движения наконечника - 120 мкм/с. Один цикл состоял из двух царапин, последовательно созданных прямым и обратным ходом. Скорость движения наконечника в приведенных выше параметрах процедуры измерения указана в середине области истирания, на краях испытываемой области (примерно 5\% длины) имеются участки ускорения и замедления движения. На каждом образце были проведены три испытания трением.

\section{3. Результаты исследований и их обсуждение}

Измерение шероховатости проводилось измерением профилей рельефа поверхности образцов. На каждом образце проведено не менее 3 профилей длиной 12,5 мм, параметры шероховатости приведены в Табл. 1 .

Очевидно, что модификация поверхности минералами привела к увеличению параметров шероховатости образцов в 2-3 раза. Максимальный перепад рельефа близок к предполагаемой толщине покрытия (10 мкм). Согласно стандарту ГОСТ 8.748-2011 (ISO 14577), измерение твёрдости следует проводить на глубине, в 20 раз превышающей параметр $R a$, в этом случае влияние шероховатости на измеряемое значение будет меньше других источников ошибки. При несоблюдении этого соотношения ожидается существенное увеличение разброса измеренных значений твердости из-за отклонения реальной площади контакта наконечника с образцом от предусмотренной в теоретической модели.

Табл. 1. Шероховатость образцов. *

Table 1. Roughness of the samples. ${ }^{*}$

\begin{tabular}{|c|c|c|c|}
\hline $\begin{array}{c}\text { Образец } \\
\text { Sample }\end{array}$ & $\begin{array}{c}R a, \text { мкм } \\
R a, \mu \mathrm{m}\end{array}$ & $\begin{array}{c}R q, \text { мкм } \\
R q, \mu \mathrm{m}\end{array}$ & $\begin{array}{c}R z, \text { мкм } \\
R z, \mu \mathrm{m}\end{array}$ \\
\hline $\begin{array}{l}\text { Титановый сплав ВТ6 } \\
\text { Titanium alloy VT6 }\end{array}$ & $0.842 \pm 0.017$ & $1.035 \pm 0.015$ & $5.335 \pm 0.085$ \\
\hline $\begin{array}{c}\text { Титановый сплав ВТ6 с модифицированным слоем } \\
\text { Titanium alloy VT6 with modified layer }\end{array}$ & $1.72 \pm 0.21$ & $2.61 \pm 0.19$ & $16.6 \pm 1.2$ \\
\hline
\end{tabular}

*B Табл. 1: Ra, мкм - среднеарифметическое отклонение; $R q$, мкм - среднеквадратичное отклонение;

$R z$, мкм - высота неровностей по 10 точкам.

${ }^{*}$ In Table 1: $R a, \mu \mathrm{m}$ - arithmetic mean deviation; $R q, \mu \mathrm{m}$ - root-mean-square deviation;

$R z, \mu \mathrm{m}$ - height of irregularities of 10 points. 
Измерения в режиме инструментального наноиндентирования проводились наконечником в форме пирамиды Берковича и были выполнены следующим образом: на каждом из полученных образцов были нанесены серии уколов с различной максимальной нагрузкой. Нагрузка подбиралась таким образом, чтобы глубина внедрения наконечника в материал составляла от 500 нм до 4 мкм. Измерения были проведены без предварительного выбора места индентирования, расстояние между точками не менее 100 мкм.

Результаты измерения твердости $Н$ и модуля упругости $Е$ приведены в Табл. 2.

Как видно из данных Табл. 2, создание минерального слоя значительно (на 45-70\%) увеличило твердость поверхности титанового сплава ВТ6. Как было указано выше, толщина модифицированного слоя составляла около 10 мкм [4], а настоящие измерения выполнены в диапазоне глубин от 1 до 4 мкм. На малых глубинах влияние подложки на измеряемые величины мала, и поэтому ею можно было пренебречь при определении средних значений. Разброс данных составляет 40-60\% от измеренных величин, что ожидаемо и обусловлено относительно большой шероховатостью образцов по сравнению с глубиной индентирования.

В настоящих измерениях методом инструментального индентирования следует ориентироваться именно на средние измеренные значения, поскольку шероховатость сильно увеличивает разброс измеряемых значений. Увеличение разброса происходит из-за того, что реальная площадь контакта может меняться в точке контакта индентора с поверхностью в зависимости от локальной топологии рельефа.

Специфика методики инструментального индентирования заключается в том, что наблюдение площади отпечатка не производится. Расчет значений твердости выполняется по диаграмме нагружения, записанной в ходе эксперимента, которая представляет собой зависимость нагрузки, приложенной к индентору, от глубины вдавливания индентора в поверхность материала. В модели, на основе которой производится обработка в соответствии с ГОСТ Р 8.748-2011, предполагается, что поверхность расположена нормально к направлению индентирования и является абсолютно гладкой. Для такой поверхности сохраняется калибровочная функция формы индентора и расчет твердости характеризуется максимальной точностью. Однако, все без исключения реальные поверхности шероховаты и волнисты, что вносит погрешность в рассчитанные значения твердости. При этом, в зависимости от схемы контакта реальная площадь контакта может быть как больше, так и меньше, чем калибровочная. Таким образом, только из-за шероховатости поверхности измеренное значение может отличаться от истинного в большую или меньшую сторону, поскольку твердость в данном методе рассчитывается как отношение приложенной нагрузки к площади контакта индентора с образцом. В настоящем эксперименте, поскольку укалывание производилось в случайные точки поверхности, целесообразно оперировать и сравнивать именно средние измеренные значения для исходной и модифицированной поверхности, а не крайние точки с учетом погрешности.

На Рис. 1-4 приведены фотографии участков износа поверхности после испытания и кривые зависимости углубления наконечника в образец от времени испытания. Значения глубины отсчитывается от уровня поверхности при первом цикле истирания. Испытания отмечены номерами на фотографиях и цветом кривой на графиках (1 - чёрная, 2 - красная, 3 - синяя).

В Табл. 3 приведен средний линейный износ образца на участке между 50 и 100 циклом испытания, $\Delta h$-линейный износ, среднее углубление наконечника за один цикл испытания трением.

Из данных Табл. 3 и Рис. 3, 4 видно, что износостойкость поверхности образца титанового сплава ВТ6, модифицированной минералами по технологии минеральных покрытий, увеличилась в 4-5 раз по сравнению с износостойкостью поверхности титанового сплава ВТ6 без модификации.

Вопросы теоретического объяснения эффектов, возникающих при легировании металлов ультрадисперсными частицами минералов природного происхождения,

Табл. 2. Механические свойства образцов.

Table 2. Mechanical characteristics of the samples.

\begin{tabular}{|c|c|c|c|c|}
\hline $\begin{array}{l}\text { Образец } \\
\text { Sample }\end{array}$ & $\begin{array}{c}\text { Нагрузка, мН } \\
\text { Loading, } \mathrm{mN}\end{array}$ & $\begin{array}{c}\text { Глубина, нм } \\
\text { Depth, nm }\end{array}$ & $\begin{array}{l}\text { Твердость } H, \text { ГПа } \\
\text { Hardness } H, \mathrm{GPa}\end{array}$ & $\begin{array}{l}\text { Модуль упругости } E \text {, ГПа } \\
\text { Elastic modulus } E, G P a\end{array}$ \\
\hline $\begin{array}{c}\text { Титановый сплав ВТ6 } \\
\text { Titanium alloy VT6 }\end{array}$ & $\begin{array}{c}60 \\
150 \\
300 \\
750 \\
1500\end{array}$ & $\begin{array}{c}720 \pm 80 \\
1170 \pm 110 \\
1750 \pm 260 \\
2820 \pm 310 \\
3980 \pm 490\end{array}$ & $\begin{array}{l}6.2 \pm 1.8 \\
5.6 \pm 1.1 \\
5.2 \pm 2.1 \\
4.8 \pm 1.1 \\
4.8 \pm 1.1\end{array}$ & $\begin{array}{l}170 \pm 50 \\
183 \pm 43 \\
180 \pm 50 \\
171 \pm 34 \\
176 \pm 32\end{array}$ \\
\hline $\begin{array}{c}\text { Титановый сплав ВТ6 } \\
\text { с модифицированным слоем } \\
\text { Titanium alloy VT6 } \\
\text { with modified layer }\end{array}$ & $\begin{array}{c}60 \\
150 \\
300 \\
750 \\
1500\end{array}$ & $\begin{array}{c}820 \pm 330 \\
1180 \pm 480 \\
1700 \pm 700 \\
3000 \pm 1500 \\
3400 \pm 800\end{array}$ & $\begin{array}{c}9 \pm 7 \\
9 \pm 5 \\
8.4 \pm 4.8 \\
7 \pm 6 \\
8.5 \pm 3.9\end{array}$ & $\begin{array}{l}140 \pm 80 \\
170 \pm 70 \\
160 \pm 60 \\
150 \pm 80 \\
180 \pm 60\end{array}$ \\
\hline
\end{tabular}


пока носят характер предположений. Возможно, что одной из причин является изменение свойств внедряемых частиц минералов при измельчении, которое может приводить к повышению поверхностной активности частиц малого размера, переходу вещества в новую модификацию, морфизацию кристаллических веществ, дегидратацию или гидратацию [15].

Также можно выделить особенности природных материалов, которые, возможно, способствуют достижению уникальных параметров поверхности, модифици-

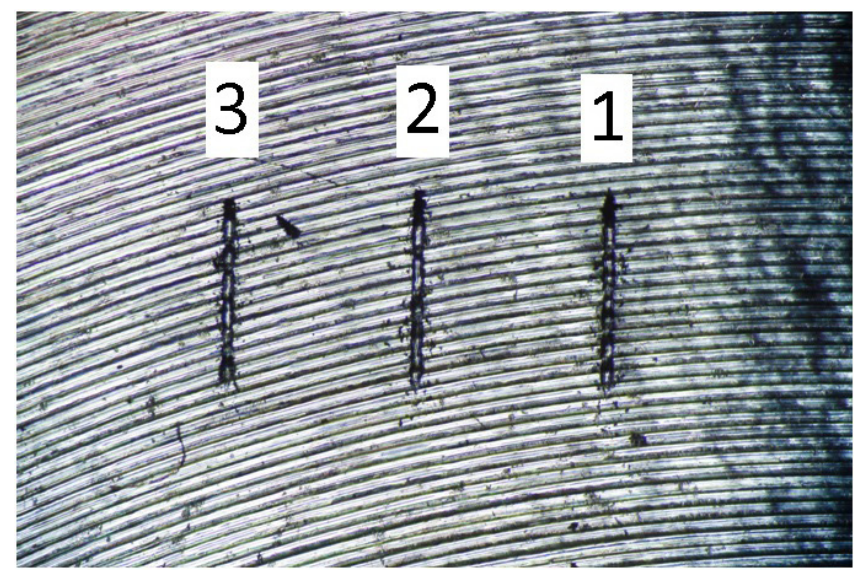

Рис. 1. Фотография (х40) поверхности образца титанового сплава ВТ6 без модификации после испытания с нагрузкой $500 \mathrm{MH}$.

Fig. 1. A photograph $(\mathrm{x} 40)$ of the surface of a VT6 titanium alloy sample without modification after testing with a load of $500 \mathrm{mN}$. рованной природными минералами [15]:

- минералы сформировались под воздействием высоких давлений и температур, которые недостижимы при промышленном получении;

- минералы получают из горных пород, содержащих значительное количество примесей, которые в ряде случаев могут быть полезными и улучшать свойства природного материала;

- минералы содержат до сотни различных атомов различных веществ в одной молекуле, при этом атомы

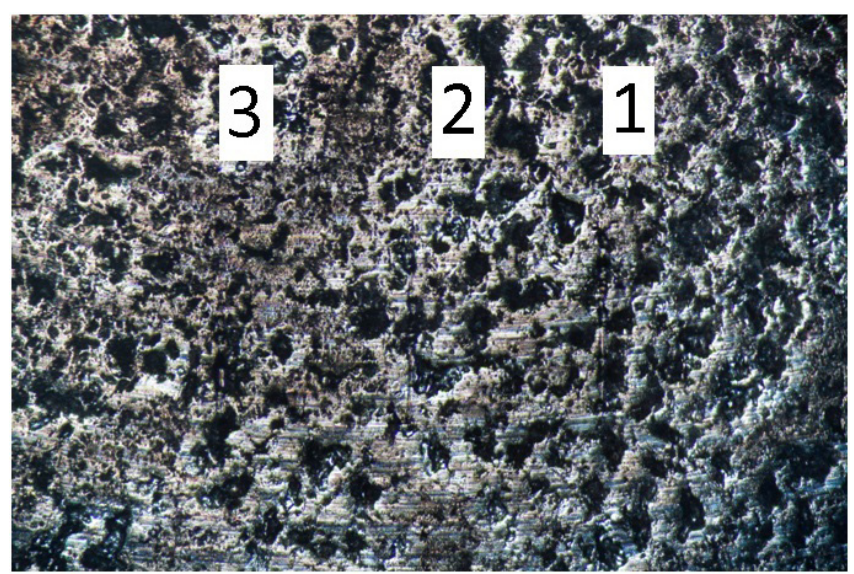

Рис. 2. Фотография (х40) модифицированной минералами поверхности образца титанового сплава ВТ6 после испытания с нагрузкой $500 \mathrm{MH}$.

Fig. 2. A photograph $(\mathrm{x} 40)$ of the surface of a VT6 titanium alloy sample with modification of the surface by minerals after testing with a load of $500 \mathrm{mN}$.

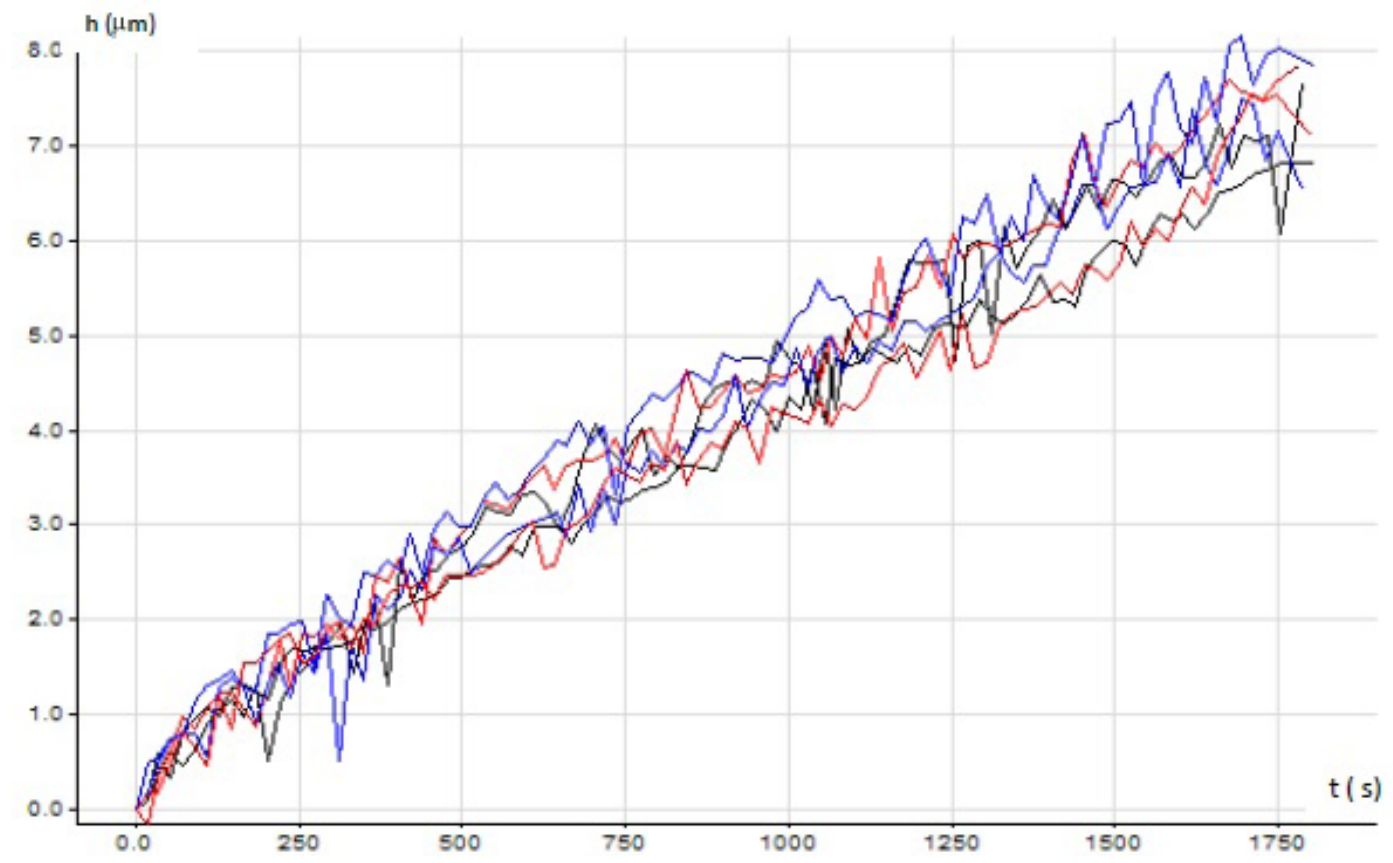

Pис. 3. (Color online) Диаграмма изнашивания поверхности образца титанового сплава ВТ6 без модификации при использовании сапфирового наконечника с нагрузкой $500 \mathrm{MH}$. Здесь $h$, мкм - значения углубления наконечника; $t, \mathrm{c}-$ время испытания. Значения глубины отсчитывается от уровня поверхности при первом цикле истирания. Испытания отмечены номерами на фотографиях и цветом кривой на графиках ( 1 - чёрная, 2 - красная, 3 - синяя).

Fig. 3. (Color online) Wearing diagram of the surface of a VT6 titanium alloy sample without modification when using a sapphire tip with a load of $500 \mathrm{mN}$. In the diagram: $h, \mu \mathrm{m}$ - value of the tip deepening; $t, \mathrm{~s}$ - test duration. The depth value is measured from the surface level during the first abrasion cycle. The tests are indicated by numbers on the photographs and the colour of the curve on the graphs $(1-$ black, 2 - red, 3 - blue). 
могут быть объединены в группы, которые могут менять свои аллотропические состояния при различном воздействии на поверхность образца или детали.

Отсутствие в настоящее время приемлемого объяснения природы особых свойств поверхности, модифицированной ультрадисперсными частицами минералов природного происхождения, не исключает использования наблюдаемых эффектов для повышения ресурса различных деталей и механизмов.

\section{4. Выводы}

После осуществления модификации поверхности образца из титанового сплава ВТ6 при помощи технологии минеральных покрытий, использующей низкотемпературные технологические операции (с локальным нагревом до $80^{\circ} \mathrm{C}$ ), твердость поверхности образца из титанового сплава увеличилась на 45 - 70\%.

Износостойкость поверхности образца из титанового сплава ВТ6, модифицированной минералами, увеличилась в 4-5 раз по сравнению с износостойкостью поверхности титанового сплава ВТ6 без модификации.

\section{Литература/References}

1. A. A. Ilyin, B. A. Kolachev, I.S. Polkin. Titanic alloys. Structure, composition, properties. Reference book. M.: VILS-MATI. (2009) 520 p. (in Russian) [А.А. Ильин, Б.А. Колачев, И.С. Полькин Титановые сплавы. Состав, структура, свойства. Справочник. М.: ВИЛСМАТИ. (2009). 520 с.]

2. M Long., Rack H. J. Biomaterials. 18, 1621 - 1639 (1998).

3. Patent RF № 2421548, 20.06.2011. (in Russian) [Патент РФ № 2421548, 20.06.2011 г.]

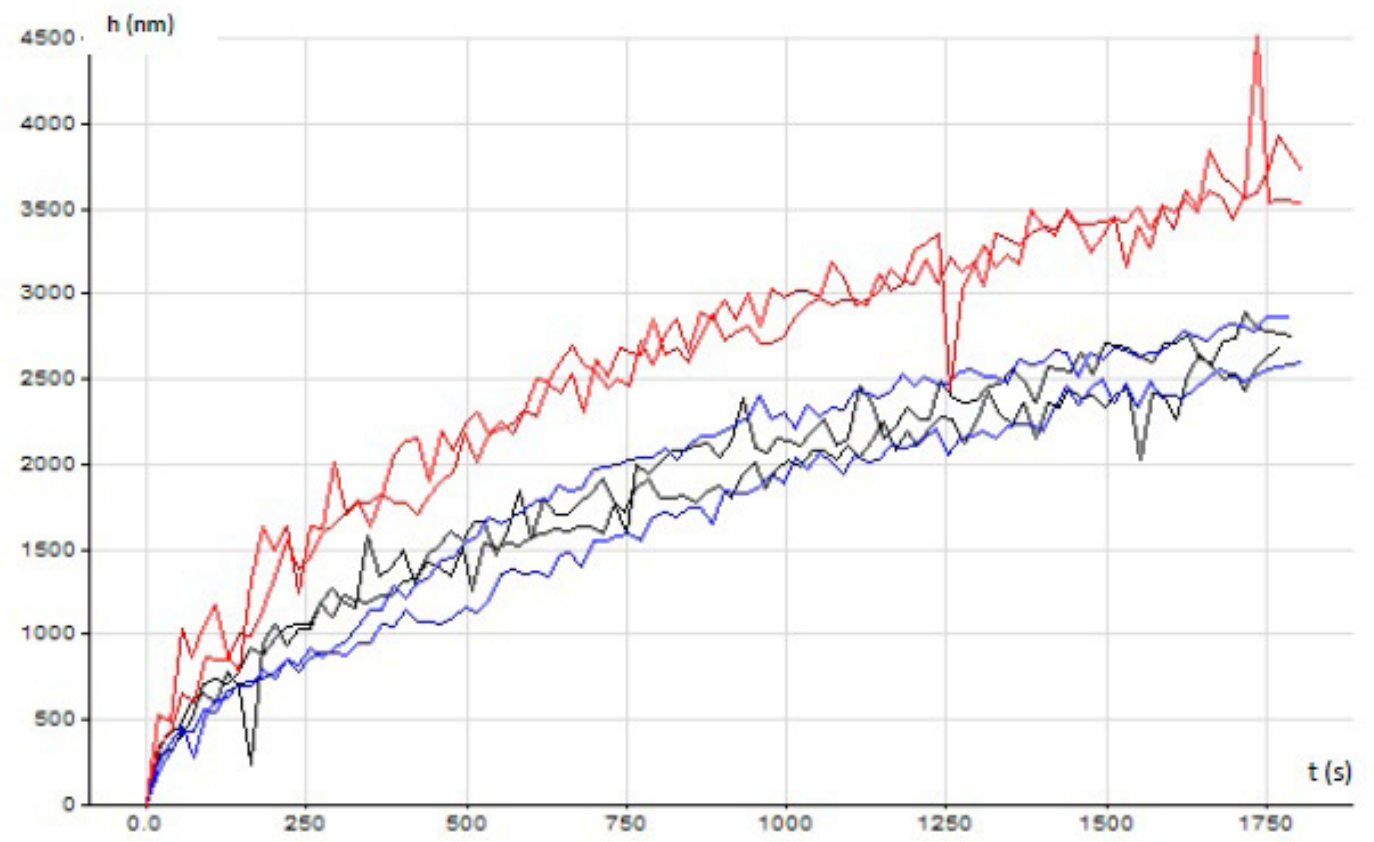

Pис. 4. (Color online) Диаграмма изнашивания модифицированной минералами поверхности образца титанового сплава ВТ6 при использовании сапфирового наконечника с нагрузкой $500 \mathrm{mH}$. Здесь $h$, мкм - значения углубления наконечника; $t$, с время испытания. Значения глубины отсчитывается от уровня поверхности при первом цикле истирания. Испытания отмечены номерами на фотографиях и цветом кривой на графиках (1 - чёрная, 2 - красная, 3 - синяя).

Fig.4. (Color online) Wearing diagram of the surface of a VT6 titanium alloy sample with modification of the surface by minerals when using a sapphire tip with a load of $500 \mathrm{mN}$. In the diagram: $h, \mu \mathrm{m}$ - value of the tip deepening, $t, \mathrm{~s}-$ test duration. The depth value is measured from the surface level during the first abrasion cycle. The tests are indicated by numbers on the photographs and the colour of the curve on the graphs $(1-$ black, 2 - red, 3 - blue).

Табл. 3. Линейный износ.

Table 3. Linear wear.

\begin{tabular}{|c|c|c|}
\hline $\begin{array}{c}\text { Образец } \\
\text { Sample }\end{array}$ & $\begin{array}{c}\text { Нагрузка, мH } \\
\text { Loading, } \mathrm{mN}\end{array}$ & $\begin{array}{c}\text { Линейный износ } \Delta h, \text { нм } \\
\text { Linear wear, } \Delta h, \mathrm{~nm}\end{array}$ \\
\hline Титановый сплав BT6 & 100 & $21.4 \pm 2.3$ \\
Titanium alloy VT6 & 500 & $64 \pm 5$ \\
\hline Титановый сплав BT6 с модифицированным слоем & 100 & $3.99 \pm 0.41$ \\
Titanium alloy VT6 with modified layer & 500 & $14.4 \pm 2.2$ \\
\hline
\end{tabular}


4. S.V. Kislov, V.G. Kislov, A.V. Skazochkin, G. G. Bondarenko, A.N. Tikhonov. Russian Metallurgy (Metally). 7, 558 - 564 (2015) (in Russian) [С. В. Кислов, В.Г. Кислов, А.В. Сказочкин, Г.Г. Бондаренко, A.H. Тихонов. Металлы. 4, 56-63 (2015).]. DOI: $10.1134 /$ S0036029515070095

5. S.V. Kislov, V.G. Kislov, A.V. Skazochkin, G.G. Bondarenko, A.N. Tikhonov. Oil and Gas. 4, 216 - 230 (2015). (in Russian) [С.В.Кислов, В. Г. Кислов, А.В. Сказочкин, Г.Г. Бондаренко, А.Н. Тихонов. Нефтегазовое дело. 4, 216-230 (2015).]

6. P. V. Balash, S. V. Kislov, A. V. Skazochkin. Innovation. 12, 95 - 105 (2015). (in Russian) [П. В. Балаш, С. В. Кислов, А. В. Сказочкин. Инновации. 12, 95 - 105 (2015)]

7. S. V. Kislov, V.G. Kislov, P.V. Balasch, A. V. Skazochkin, G. G. Bondarenko and A.N. Tikhonov. Materials Science and Engineering/IOP Conf. Series: Materials Science and Engineering 110 (2016). DOI: 10.1088/1757899X/110/1/012048

8. S. V. Kislov, V. G. Kislov, P. V. Balasch, A. V. Skazochkin. Pump. Turbines. Systems. 4, 35-45 (2016). (in Russian) [С.В. Кислов, П.В. Балаш, В.Г. Кислов, А.В. Сказочкин. Насосы. Турбины. Системы. 4, $35-45$ (2016).]

9. S. V. Kislov, V. G. Kislov, P. V. Balasch, A. V. Skazochkin. Materials of the International Conference «The prospects of development of new technologies in power industry of Russia», Moscow. M.: VTI, (2016) p. 229-234. (in Russian) [С.В. Кислов, В. Г Кислов, П.В. Балаш, A.В. Сказочкин. Материалы Междунар. конф. «Перспективы развития новых технологий в энергетике России», Москва. М.: ОАО «ВТИ», 2016. с. $229-234]$

10. S. V. Kislov, V. G. Kislov, P. V. Balasch, A. V. Skazochkin. Chemical technique. 8, 20-30 (2016). (in Russian) [С. В. Кислов, П. В. Балаш, В. Г. Кислов, А. В. Сказочкин. Химическая техника. 8, 20 - 30 (2016)]

11. A. Useinov, K. Gogolinskiy and V. Reshetov. International J. of Mater. Research. 7, 968 - 972 (2009).

12. A. Useinov. Instruments and Experimental Techniques. 1, 134 - 138 (2004). (in Russian) [А. Усеинов. Приборы и техника эксперимента. 1, 134 - 138 (2004)]

13. A. Useinov, K. Kravchuk, N. Lvova. Nanoindustry. 4, 46-50 (2011). (in Russian) [А. Усеинов, К. Кравчук, Н. Львова. Наноиндустрия. 4, 46 - 50 (2011).]

14. A. Useinov, C. Useinov. Nanoindustry. 6, 28 - 32 (2010). (in Russian) [А. Усеинов, С. Усеинов. Наноиндустрия. 6, $28-32$ (2010).]

15. V.V. Grushev, S. Yu. Lazarev Industrial application of mineral coatings and ultrasonic processing. Chita: ZabGU. (2012) 144 p. (in Russian) [B. B. Грушев, С.Ю. Лазарев Промышленное применение минеральных покрытий и ультразвуковой обработки. Чита: ЗабГУ (2012) 144 с.] 